\title{
Integrating Climate Change in the Urban Planning Process - A Case Study
}

\author{
Stefan Sander ${ }^{1}$, Holger Hoppe ${ }^{2}$, and Sascha Schlobinski ${ }^{3}$ \\ ${ }^{1}$ Stadtverwaltung Wuppertal \\ stefan.sander@stadt.wuppertal.de \\ ${ }^{2}$ DR. PECHER AG \\ Holger. Hoppe@pecher. de \\ ${ }^{3}$ cismet $\mathrm{GmbH}$ \\ sascha.schlobinski@cismet.de
}

\begin{abstract}
The ongoing European collaborative project SUDPLAN is targeted on the development of a software framework that allows the integration of climate change aspects in urban planning processes. Besides the implementation of the generic modules SUDPLAN comprises the implementation of four tangible pilot applications of the framework, one of them in the German City of Wuppertal. This "Wuppertal pilot" deals with urban storm water management and the prevention of infrastructure damages under present and future climate conditions. It can be considered as a case study for the integration of climate change in an actual, long-term urban planning process. This article describes the basic conditions of the case study and the building blocks of the intended decision support environment for urban planners, including the local models used for the simulation of storm water runoff, both in the sewers and on the surface.
\end{abstract}

Keywords: climate change downscaling, model integration, urban planning modelling experiments, SDI.

\section{Introduction}

The effects of climate change will expose European cities to environmental pressures ranging from heat waves to increased heavy rain falls e. g. [1]. Many processes in environmental planning are affected by these effects. This is valid particularly for the dimensioning of sewer systems and flood protection based on precipitation-runoffmodels [2]. Therefore sustainable urban planning needs to take climate change into account as an integral part of the planning and decision making process [3], [4]. Obviously this requires access to global and local climate change information and the possibility to include this information in the individual workflows of local planners and decision makers.

In the present case study we focus on the use of climate change information in a real, long-term urban planning process. Due to the effects of climate change the city of Wuppertal (Germany) faces extremely localized runoff events from increased heavy, short-term rainfall. The potential damage of public infrastructure and of 
private property is a major concern for the city managers. The needs for future investments are huge, considering that the city has to cope with runoff from many natural and canalised creeks and a sewer system of 1,500 kilometers. As in most urbanised areas, in the city of Wuppertal the dynamics of urban development have eclipsed the preservation of natural watercourse patterns. Numerous discharging streams have become part of the sewer system in the course of industrialisation. Apart from a few exceptions, a separate sewer system is used for domestic drainage in Wuppertal [5].

In a nutshell, the present case study is based upon two guiding ideas:

- The first is the development of a tool that enables the responsible planners to define and run simulations of 1D-2D sewer and surface runoff in the course of heavy storm water events and to visualise the results of these model runs.

- The second is to consider the effect of climate change on the future rainfall patterns by using downscaled rainfall data that is input to the simulations.

\section{Case Study - Basic Conditions}

The city of Wuppertal, a town with approximately 350,000 residents, is the biggest town in Germany that is situated in hill country (from 98 to $353 \mathrm{~m}$ above mean sea level). It is located in the steep, narrow, and long valley of the river Wupper. There are several creeks on both sides of this valley that open into the storm water sewage system before they finally end in the Wupper. During an extreme rainfall event that is exceeding the design storm events [6] the city's storm water sewage system might be blocked by those swollen creeks causing the precipitation to run off on the surface. The storm water runoff may thereby affect valuable public infrastructure and private property. Due to the complex geography where a heavy rainfall event might occur is completely unpredictable and therefore whether there will be flooding and where it will run off is unknown.

\subsection{Objectives}

Up to now the mid- and long-term planning of the storm water sewage system has been accomplished with iterative model runs of a hydrological model (for the natural creeks) and a hydrodynamical model (for the canalised creeks and sewage system). This planning process is called "Generalentwässerungsplanung" (GEP), which could be translated as 'General Drainage Strategy'. Wuppertal's main objectives are as follows:

The first main objective is to update the existing GEP for all areas in Wuppertal in the next several years.

The second main objective is the modelling of surface runoff during heavy rainfall events that should be integrated into the planning process. To achieve this objective, among others, a combined 1D-2D-hydrodynamical model has to be used to detect the critical spots (i. e. those with a high risk of flooding plus valuable and vulnerable facilities).

The third main objective is to mitigate the risk of flooding for the detected critical spots. The traditional strategies to achieve this are either the enlargement of the 
profiles of the sewage system or the construction of retention basins. Given these two options the potential needs for investments would be immense, considering that the city faces the water runoff from 350 kilometres of creeks (over 800 creek sections) and 650 kilometres of storm water sewer system. An alternative and much more costefficient strategy is to look for localised planning options which are likely to prevent damage. Examples of such structural measures are the alteration of street profiles by means of higher road kerbs or the installation of mobile or stationary walls.

Therefore the fourth main objective is to find the most cost-efficient measures for flood risk mitigation for each critical spot. These measures must reduce the probability of damage, but should still be practical to implement, especially within the increasing financial constraints of the city. See [7] and [8] for more information on Flood risk management.

The fifth main objective is to provide the responsible planners and hydraulic modellers in Wuppertal with a tool that enables them to simulate a multitude of scenarios with the model components for the sewer system and surface runoff, both to detect the critical spots and to simulate the effects of different structural measures at the critical spots. The tool should be able to store the parameters and results of such a model run and to visualise the results.

\subsection{Requirements and Deficiencies}

Climate change is expected to have an increasing impact on the frequency of heavy storm water events in Wuppertal and possibly on the maximum intensity of such events as well. This makes it necessary to include climate change effects both in the long-term planning of the storm water sewage system and in the simulations of surface runoff. In other words, the intensity and duration of a rainfall event of a given probability (e. g. one time in 30 years) is a crucial parameter in every single modelling experiment. If climate change is ignored in these simulations, the suggested structural measures would possibly not be effective in the long run.

Currently the main deficiency is the lack of any systematic knowledge about the critical spots with regard to flooding after heavy storm water events. Wuppertal intends to establish this knowledge in the forthcoming years. But there is still a deficiency in understanding the dynamic processes of floods triggered by heavy storm water events in combination with possible climate change effects. Wuppertal expects to get a deeper understanding of this by running a multitude of modelling experiments, with the model component for surface runoff, for different catchment areas and with different precipitation patterns.

\subsection{Supported Tasks}

The intended simulation tool will allow an analyst to predict areas of urban flooding within the City of Wuppertal for two purposes. The first is to be able to inform owners of low-lying assets about possible threats ("Flood Risk Assessment"). For example, the owners of a commercial building that contains telecommunications equipment in the cellar might be informed that (in the future) their assets might be under increasing risk of inundation and destruction. This will give them an opportunity to undertake changes to protect this equipment from such risks. The second is to consider 
possible alterations that might reduce the risk of damage due to flooding ("Flood Risk Mitigation"). In this case there might be infrastructure changes which could be planned to prevent damage anticipated by the first analysis. For example, kerbs might be raised, barrier walls could be erected, or storm water retention basins might be constructed. While the primary concern is in regard to flood events likely to occur within a near-term horizon (e. g. a return period of 5 to 30 years), there is also interest in the long-term ramifications of global climate change with respect to urban flooding. Both of these tasks have as their primary goal the protection of both personal and public property from damage due to urban flooding during storm events.

\subsection{Targeted Users}

There are two types of primary users who will make regular and direct use of the intended simulation tool: Storm Water Managers and System Administrators. Wuppertal's storm water managers are hydraulic modellers employed either by the City of Wuppertal or the Wuppertaler Stadtwerke AG, the municipal utility that runs the sewage system on behalf of the City of Wuppertal. These individuals are very comfortable with computers. As modellers they will want to interact with the hydraulic models used and they may have some familiarity with precipitation-runoff-models. However, they will likely have little to no experience with global climate models. They may or may not have sophisticated GIS experience. The System Administrators are City of Wuppertal staff members who are very comfortable with computers, computer networks, and software installation. They are sophisticated GIS users, comfortable with installing and configuring both spatial and non-spatial databases. In general they have no expert knowledge regarding climate, precipitation, or urban precipitation-runoff-models.

Secondary users of the intended simulation tool consist of those property owners whose assets might be endangered by flooding. Property owners in Wuppertal will be shown results by the planners and may interact with the system together to engage in "what if" scenario sessions. They may or may not have technical backgrounds.

In addition city politicians/managers and the general public will interact with the system only in the sense that they will be shown results or reports whose content was produced by the system (tertiary users).

\section{The Solution}

The Wuppertal case study was performed as part of the ongoing FP7 ICT project SUDPLAN [9]. SUDPLAN's two main projected software results are:

1. The SUDPLAN Scenario Management System (SMS) which is a highly interactive graphics-based decision support environment [10] that allows the end-user to access environmental information and to manage both the model runs and related information (Figure 1).

2. The Common Services that provide environmental information for European cities under present and future climate scenarios, in support to long-term urban planning. 
3. Common Services deliver downscaled information on extreme rainfall events, rainfall time series, hydrology and air quality that can be used to parameterize and/or set boundary conditions for local models
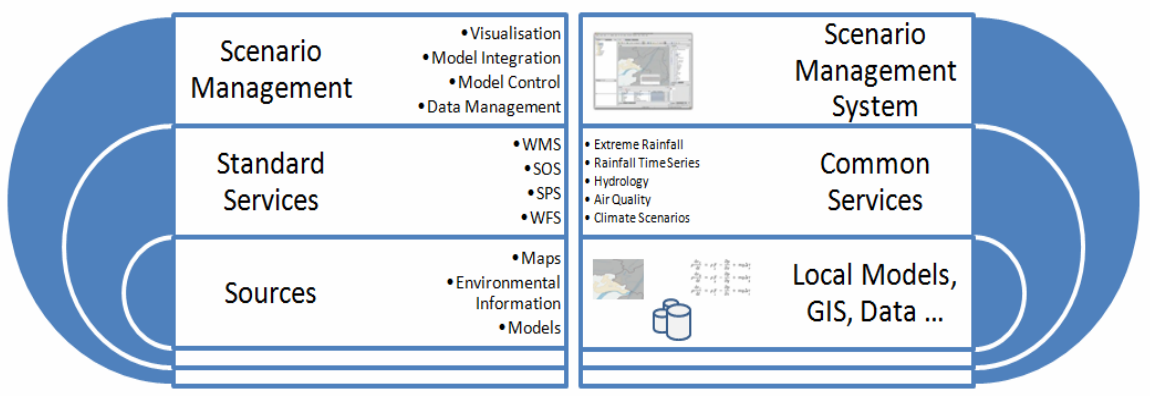

Fig. 1. SUDPLAN Architectural Layers

The access to sources of information regardless of their origin (model, data base ...) is decoupled via a service layer consisting of standard compliant services, and is therefore to a large extent independent of the underlying source. This is the key to achieving a significant degree of transferability [11] of the project results to other European municipalities.

The Scenario Management System and some of the the Common Services are integral parts of the presented urban planning workbench that is called "Wuppertal pilot" in the terminology of the SUDPLAN project (cp. Figure 2).

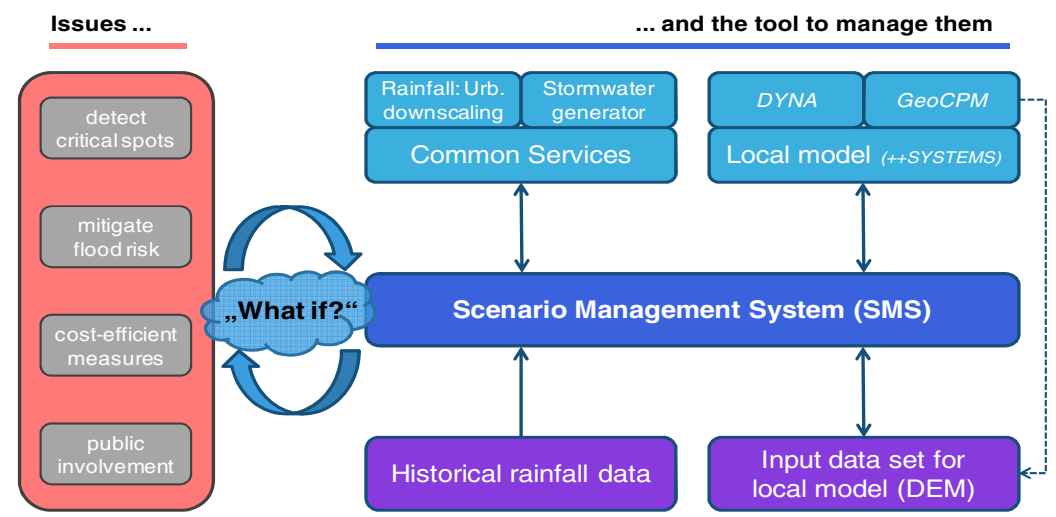

Fig. 2. SUDPLAN Wuppertal pilot for Urban Stormwater Management

To tackle the issues described in section 2.1 the Wuppertal municipality will use the Wuppertal pilot to run simulations of 1D-2D sewer and surface runoff in the course of heavy storm water events. Running such a simulation involves the execution of external local models provided by the software products DYNA (for sewer runoff) 
and GeoCPM (for surface runoff). Both are components for ++ SYSTEMS, a geographical information system (GIS) for the urban water management domain (cp. section 3.2). In order to keep the processing time to the order of a few hours a model run deals with the catchment area of merely an individual creek rather than the whole area of Wuppertal. The model runs will be defined by means of the SMS. Both the definition and the result of a model run will be stored in the repository of the SMS.

The input data set for the local models includes precipitation data, a description of the sewer network needed for the execution of DYNA, and an optimized highresolution digital elevation model (DEM) necessary for the execution of GeoCPM. The setup of the DEM in the form of a triangulated irregular network with detailed modelling of all relevant vertical structures (e. g. buildings or road kerbs) is a single yet labor-intensive preparatory task that has to be carried out for each catchment area. GeoCPM comprises tools to support this work (cp. dotted line in Figure 2).

The Wuppertal pilot will use the two Common Services concerning precipitation that will be established in SUDPLAN to simulate intense short-term rainfall under the predicted future climatic conditions: "Urban downscaling" (already implemented) and "Stormwater generator" (under development). To use these services it is necessary to provide historical high resolution precipitation data for the area that a simulation covers. The SMS again will be used to upload these data to the Common Services, to receive the predicted precipitation data (time series or intensity-duration-frequency curves) and to insert it into the input data set for the local models.

\subsection{The Urban Planning Workbench - Supporting the Planning and Decision Making Process}

The urban planning workbench has the objective of supporting seamless integration of and access to models and information necessary for urban planning processes. Essential to this is the ability to manage information related to model experiments [11] and to compare and evaluate model results (different scenarios). Moreover, it provides advanced visualisation independent of the model software and a number of graphical user interface components to access standard compliant services (OGC WMS, WFS, SPS, SOS).

The software is based on the cids Geointegration Platform by cismet GmbH (cismet.de) that provides the means to flexibly combine Climate Model, Local Model and GIS information and therefore to effectively support urban decision making and planning processes [12],[13].

\subsection{Integration of Local Models - Merge the City Planner and Model Results}

The prediction of flooding in urban areas caused by extreme rain events is an important challenge in the effort to secure the values and fulfil present regulations [6]. Traditional 1D-hydrodynamic sewer simulation models provide the main information for robust flood protection. For further and detailed investigations the interaction between sewer and surface runoff has to be considered by using a bi-directional connected model of the sewer system and surface runoff with combined 1D-2D models. Therefore detailed information about the relevant sewer structures and the structures on the surface are needed (e. g. a classical sewer model combined with airborne laser scan 


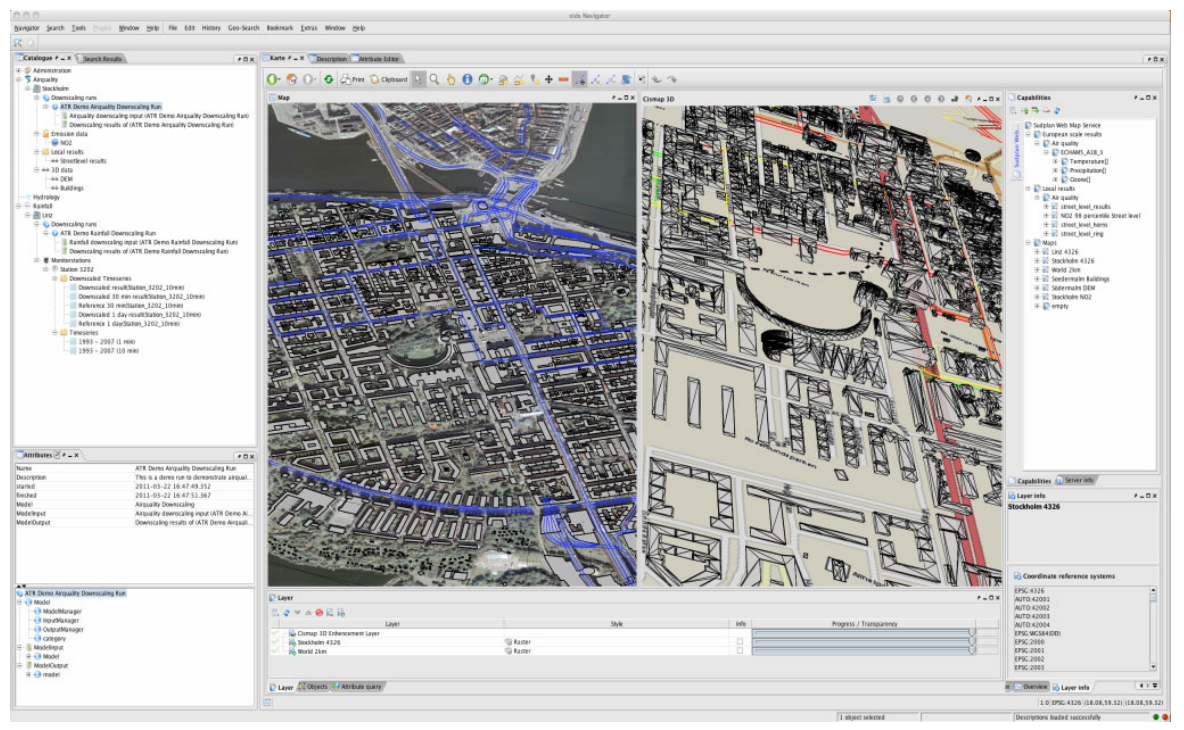

Fig. 3. SUDPLAN Scenario Management System based on the cids Geointegration Platform

data and local topographical survey). As the current calculations for the sewer system in Wuppertal are carried out with the well-established 1D(3D)-hydrodynamic model ++ Systems-DYNA by Pecher Software (Erkrath, Germany) and tandler.com (Buch am Erlbach) the combined 1D-2D calculations are carried out with the newly developed software model DYNA-GeoCPM by tandler.com. Figure 4 shows a visualisation of first results attained by means of a combined DYNA-GeoCPM model run for the testcatchment area. Further description of the approaches for modelling of urban flooding can be found in [14]. Integration into the Urban Planning Workbench is accomplished by exposing the model's functionality via a service interface with the objective of being able to obtain a high degree of modelling software independence. This will allow, for example, the use of different models in the same workbench or the replacement of modelling components, if needed, without effects on the overall workbench.

\subsection{Integration of Climate Change Information in City Planning Processes}

To include climate change effects in modelling experiments the software that is used for the definition of the parameters of such an experiment needs to be able to process information concerning climate change, e. g. future precipitation data.

The Wuppertal pilot will use the SUDPLAN Common Services to simulate intense short-term rainfall under the predicted future climatic conditions, as it is crucial to the modelling of surface runoff to consider the effect of climate change on future precipitation patterns. To use the urban downscaling service it is necessary to provide local historical high resolution precipitation data (cp. section 3). The required rainfall data are available for two gauging stations in the wastewater treatment plants "Buchenhofen" (keeping records since 1960) and "Schwelm" (keeping records since 1970). 


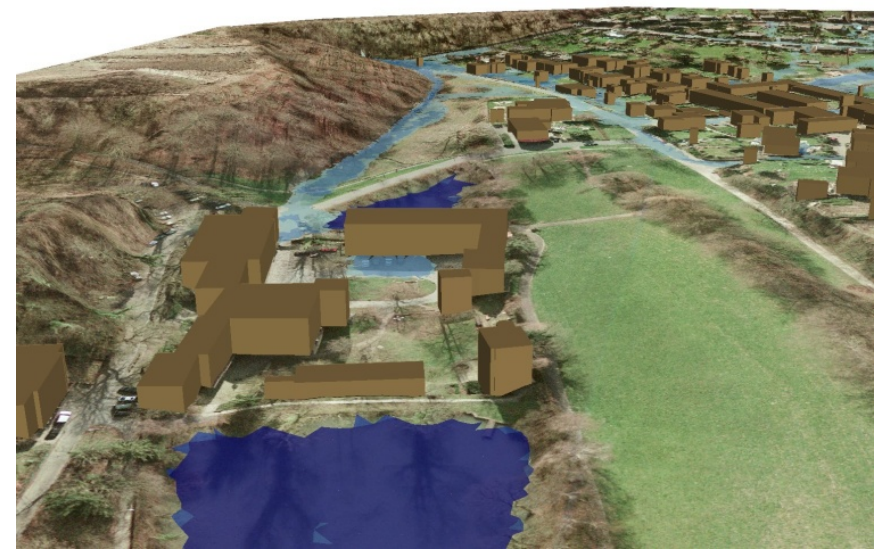

Fig. 4. First results of the 1D-2D-hydrodynamic model DYNA-GeoCPM for the test-catchment area "Lüntenbeck" in Wuppertal [15]

The storm water generator will take the starting point and the direction of a heavy storm water event as input, along with current maximum rainfall intensity. The output of the generator will be a grid of time variation curves for precipitation, thus describing the spatiotemporal progression of a synthetic storm water event for present or future climate conditions. This service will provide an easy way to generate precipitation data for the different runs of the surface run-off model and to study the influence of the direction a storm water event is moving in.

\subsection{Benefits of the Wuppertal Pilot}

The main focus of the present case study lies in the establishment of an easy to use decision support environment that allows planners both in the Wuppertal municipality and in cooperating organisations to introduce climate change considerations into their everyday modelling work. Climate change is a complex matter and a municipality is not expected to have any expertise in this domain. Therefore the knowledge threshold for dealing with climate change effects has to be lowered significantly to achieve a sustainable change of the planning workflows. Introducing a tool like the SUDPLAN Wuppertal pilot seems to be a promising way to reach this goal.

The availability of the Wuppertal pilot will enhance the working environment of the planners in many different ways compared to the tools currently at hand: it will enable them to identify cost-efficient planning options for flood risk mitigation in Wuppertal by playing what-if games in a highly interactive way. Moreover, they will be able to share the results of their modelling work with city managers, politicians and the general public by means of vivid 3D/4D visualisations that go far beyond current approaches used by standard modelling software.

Other benefits follow from the generic architecture of the SUDPLAN software. This will enable the City of Wuppertal to develop applications similar to the Wuppertal pilot in a quick and cost-effective way. The SUDPLAN software will provide new 
generic components for Wuppertal's Spatial Data Infrastructure (SDI). These components will comprise services (e.g. access control and security) and application components (e. g. for 3D visualisation). The new components will offer further application options for Wuppertal's SDI and thus will intensify the use of the existing spatial data.

\section{Summary and Future Research}

The present case study illustrates the introduction of climate change considerations in a long-term urban planning process. The featured example is urban storm water management with an emphasis on the prevention of infrastructure damages. The initial point of the study is the implementation of a tool that enables the storm water managers to deal with tangible climate change predictions and to use them as input data for local models. Generic building blocks for such a software system are under development in the ongoing FP7 ICT project SUDPLAN which runs from January 2010 until December 2012. The climate change information in SUDPLAN comes from the Common Services, a set of standard compliant Web Services that supply environmental information under present and future climate conditions on the scale of a European city. For the case study services are used that deliver downscaled information on extreme rainfall events and rainfall time series. The second predominant SUDPLAN module is the Scenario Management System (SMS) that is used to communicate with the Common Services, to execute local models and to store and visualise the results of the model runs, all in a highly interactive manner. The application of these generic components for the case study - the so-called Wuppertal pilot - is part of SUDPLAN as well. It integrates sophisticated local models (DYNA/GeoCPM) that allow combined modelling of the sewer system and surface runoff for different storm water events. In order to get reliable results for the surface runoff an optimized highresolution digital elevation model (DEM) has to be compiled for each catchment area that is subject of a model run. These are derived from high resolution airborne laser scan data that are available for the whole of Wuppertal.

For the future, the City of Wuppertal envisions a city wide standard that allows the city planners to easily combine models with the data sources necessary for their execution and to be able to create modelling chains consisting of several models linked together. This standard will define a common interface for new modelling components and thus will ensure that new models can be seamlessly integrated in the city's information infrastructure.

\section{Acknowlegments}

SUDPLAN is a Collaborative Project (contract number 247708) co-funded by the Information Society and Media DG of the European Commission within the RTD activities of the Thematic Priority Information Society Technologies. 


\section{References}

1. IPCC, Fourth Assessment Report Climate Change 2007: Synthesis Report (2007), http: / / www.ipcc.ch/pdf/assessment-report/ar4/syr/ar4_syr.pdf (visited March 23, 2011)

2. Hoppe, H.: Impact of input data uncertainties on urban drainage models: climate change a crucial issue? In: Conference Proceedings. 11th International Conference on Urban Drainage, Edinburgh, Scotland, UK (2008)

3. Ashley, R.M., Balmforth, D.J., Saul, A.J., Blanksby, J.D.: Flooding in the future - predicting climate change, risks and responses in urban areas. Wat. Sci. Tech. 52(5), 265-273 (2005)

4. Ashley, R.M., Tait, S.J., Styan, E., Cashman, A., Luck, B., Blanksby, J., Saul, A.: L. Sandlands, Sewer system design moving into the 21 st century - a UK perspective. Wat. Sci. Tech. 55(4), 273-281 (2007)

5. Hoppe, H., Messmann, S., Giga, A., Gruening, H.: A real-time control strategy for the separation of highly polluted storm water based on UV-Vis online measurements - from theory to operation. In: Proceedings of the 7th International Conference on Sustainable Techniques and Strategies in Urban Water Management, NOVATECH 2010, Lyon, France (2010)

6. DWA, STANDARD DWA - A 118E Hydraulic Dimensioning and Verification of Drainage Systems. DWA, Hennef (2006)

7. Arun, K.: Handbook of Flood Management: Flood Risk Simulation, Warning, Assessment and Mitigatio, vol. I. SBS Publisher (2009)

8. Schanze, J., Zeman, E., Marsalek, J. (eds.): Flood Risk Management: Hazards, Vulnerability and Mitigation Measures. NATO Science Series: IV: Earth and Environmental Sciences. Springer, Netherlands (2006)

9. Denzer, R.: A Decision Support System for Urban Climate Change Adaptation. In: Proceedings of the 44th Hawaii International Conference on System Sciences (HICSS-44), CDROM. IEEE Computer Society, Los Alamitos (2011)

10. Swayne, D.A., Denzer, R., Lilburn, L., Purvis, M., Quinn, N.W.T., Storey, A.: Environmental Decision Support Systems - Exactly what are they?, Environmental Software Systems. Environmental Information and Decision Support, vol. 3, pp. 257-268. Kluwer Academic Publishers, Dordrecht (2000)

11. Denzer, R.: Generic Integration of Environmental Decision Support Systems \& State-ofthe Art. Journal Environmental Modelling \& Software, EMS (2004)

12. Denzer, R., Güttler, R., Swayne, D.A.: Integrated Spatial Decision Support, Environmental Software Systems. Environmental Information and Indicators, vol. 4, pp. 227-235 (2001)

13. Güttler, R., Denzer, R., Houy, P.: User Interfaces for Environmental Information Systems - Interactive Maps or Catalog Structures? Or Both? Journal Advances in Environmental Research 5, 345-350 (2001)

14. Obermayer, A., Guenthert, F.W., Angermair, G., Tandler, R., Braunschmidt, S., Milojevic, N.: Different approaches for modelling of sewer caused urban flooding. Wat. Sci Tech. 62(9), 2175-2182 (2010)

15. Pecher, K.H., Hoppe, H.: Future Design of Sewer Systems (Kuenftige Bemessung von Kanalisationen). Korrespondenz Abwasser Abfall 58(2), 121-127 